\title{
TERAPIA BIOLÓGICA EN PATOLOGÍA PULMONAR Parte I: Generalidades y Clasificación \\ Parte II: Terapias Específicas en Asma, Epoc, Enfermedad Pulmonar Paringuematosa Difusa, Cáncer Pulmonar
}

\author{
Munar María Angélica ${ }^{1}$, Pantoja Jaime Andréss', Santacruz Juan Camilo ${ }^{1}$, Villate Ana María ${ }^{2}$, Bastidas Alirio \\ Rodrigo ${ }^{3}$, Giraldo Luis FerNANDO \\ ${ }^{1}$ Médicos Internos, Servicio de Neumología, Clínica Universidad de La Sabana, Chía, Cundinamarca, Colombia. \\ ${ }^{2}$ Médica, Residente Medicina Interna II año, Servicio de Neumología, Clínica Universidad de La Sabana, \\ Chía, Cundinamarca, Colombia. \\ ${ }^{3}$ Médico y Cirujano, Internista, Neumólogo, Epidemiólogo Clínico, Master Epidemiología (c), Servicio de Neumología, \\ Clínica Universidad de La Sabana, Chía, Cundinamarca, Colombia. \\ ${ }^{4}$ Médico y Cirujano, Internista, Neumólogo, PhD Investigación Médica Aplicada (c), Director Departamento Integrado \\ de Investigación, Facultad de Medicina, Universidad de La Sabana, Chía, Cundinamarca, Colombia.
}

\section{Recibido: Septiembre 1 de 2012 Aceptado: Noviembre 20 de 2012}

\section{Resumen}

El avance de la investigación médica, en los campos de la biología molecular y la ingeniería genética, ha traído consigo el desarrollo de una serie de nuevos medicamentos dirigidos a bloquear diferentes vías de la respuesta inmune celular. La terapia biológica, nombre con el cual se reconoce a estos nuevos medicamentos, ofrece una nueva oportunidad terapéutica para el manejo de enfermedades crónicas progresivas.

En las enfermedades pulmonares crónicas como el asma, la enfermedad pulmonar obstructiva crónica (EPOC), la enfermedad pulmonar parenquimatosa difusa (EPPD) y el cáncer de pulmón, el tratamiento con medicamentos biológicos ha aportado importantes avances para comprender con mayor claridad estas enfermedades y en algunos casos gracias a la eficacia de los mismos, mejorar la calidad de vida de los pacientes que las presentan. Debido al número cada vez mayor de medicamentos de terapia biológica y su aplicación terapéutica creciente en enfermedades inflamatorias crónicas y cáncer, creemos necesario revisar su estado actual en el manejo de la patología pulmonar crónica.

Palabras claves: Agentes biológicos, anticuerpos monoclonales, inmunoterapia, inmunomodulación, mecanismo de acción, presentación de antígeno, asma, enfermedad pulmonar obstructiva crónica (EPOC), enfermedad pulmonar parenquimatosa difusa (EPPD), cáncer de pulmón.

\begin{abstract}
The advancement of medical research in molecular biology and genetic engineering has given rise to the development of new drugs aimed at blocking different pathways of cellular immune responses. Biological therapy is a new therapeutic option for progressive chronic disease management. In chronic lung diseases such as asthma, chronic obstructive pulmonary disease (COPD), diffuse parenchymal lung disease (DPLD) and lung cancer, treatment with biologics has made important advances in the understanding of these diseases, and in some cases, due to their effectiveness, has contributed to the improvement in life quality of patients who suffer them. Due to the increasing number of biolo-
\end{abstract}

*Correspondencia: mariamugo@unisabana.edu.co - jaime.pantoja@unisabana.edu.co, santa89@hotmail.com - anavillate@hotmail.com aliriorodrigo@yahoo.com* - luisfgiraldo@gmail.com - Código UNESCO: 3205.08 Neumología 
gical therapy drugs and their therapeutic application in chronic inflammatory diseases and cancer, it is relevant to review their current status in the management of chronic lung diseases.

Key words: Biological agents, monoclonal antibodies, immunotherapy, immunomodulation, mechanism of action, antigen presentation, asthma, chronic obstructive pulmonary disease (COPD), diffuse parenchymal lung disease (DPLD), lung cancer.

\title{
TERAPIA BIOLÓGICA EM PATOLOGÍA PULMONAR
}

\begin{abstract}
Resumo
O avanço da pesquisa médica, nos campos da biologia molecular e da engenharia genética, trouxe consigo o desenvolvimento de uma série de novos medicamentos dirigidos a bloquear diferentes vias da resposta imune celular. A terapia biológica, nome com o qual são conhecidos estes novos medicamentos, oferece uma nova oportunidade terapêutica para o tratamento de doenças cônicas progressivas. Nas doenças pulmonares crônicas como a asma, a doença pulmonar obstrutiva crônica (DPOC), a doença parenquimatosa difusa pulmonar (DPDP) e o câncer de pulmão, o tratamento com medicamentos biológicos tem contribuído com importantes avanços para compreender com maior claridade estas doenças e em alguns casos graças à eficácia dos mesmos, melhorar a qualidade de vida dos pacientes que as apresentam. Devido ao número cada vez maior de medicamentos de terapia biológica e sua aplicação terapêutica crescente em doenças inflamatórias crônicas e câncer, acreditamos que é necessário revisar seu estado atual no tratamento da patologia pulmonar Crônica.
\end{abstract}

Palavras chave: Agentes biológicos, anticorpos monoclonais, imunoterapia, imunomodulação, mecanismo de ação, apresentação de antígeno, asma, doença pulmonar obstrutiva crônica (DPOC), doença parenquimatosa difusa pulmonar (DPDP), câncer de pulmão.

\section{Definición}

Terapia biológica: Son todos los medicamentos derivados de organismos vivos, que contienen glucosa, proteínas, ácidos nucleídos, células o tejidos donde su mecanismo de acción consiste en mediar reacciones inmunológicas específicas a través de citoquinas recombinantes, interleuquinas, factores de crecimiento, anticuerpos y proteínas de fusión (1-8).
Las características farmacológicas de los medicamentos biológicos se resumen en el gráfico

\section{Nomenclatura:}

La nomenclatura en terapia biológica consta de cuatro partes, la primera es un prefijo variable, seguido del sitio de acción, origen del compuesto seguido finalmente del tipo de molécula. A continuación en la tabla 1 se

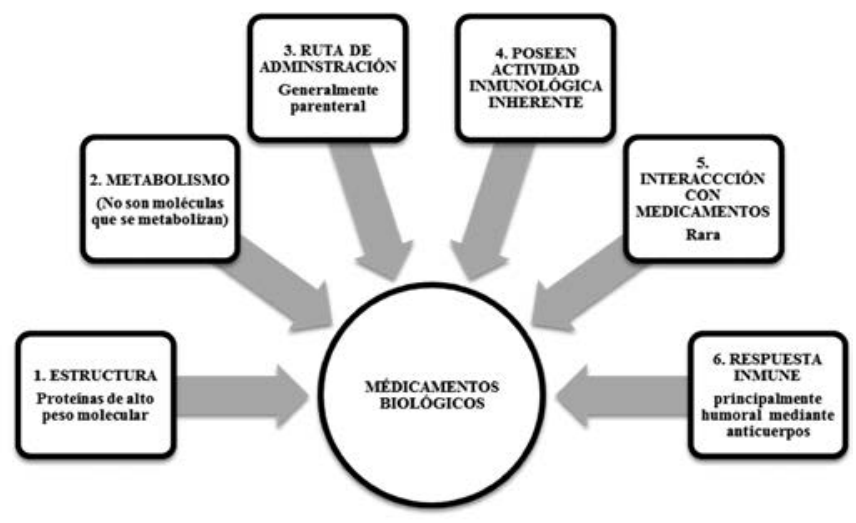

Figura 1. Características generales de los medicamentos biológicos (6, 9-13). 
describe la nomenclatura utilizada para terapia biológica en patología pulmonar.

Tabla 1. Nomenclatura (5, 10-14).

\begin{tabular}{|l|l|}
\hline Nomenclatura & \multicolumn{1}{|c|}{ Descripción } \\
\hline a. Cept & $\begin{array}{l}\text { Fusión entre el receptor y la porción FC de Ig } \\
\text { G1 humana, secuestra el ligando circulante. }\end{array}$ \\
\hline b. Mab & Anticuerpo monoclonal (mAb) \\
\hline c. Ximab & Anticuerpo monoclonal quimérico. \\
\hline d. Zumab & $\begin{array}{l}\text { Anticuerpo humanizado, similar a la estructura } \\
\text { de la Ig G humana }\end{array}$ \\
\hline
\end{tabular}

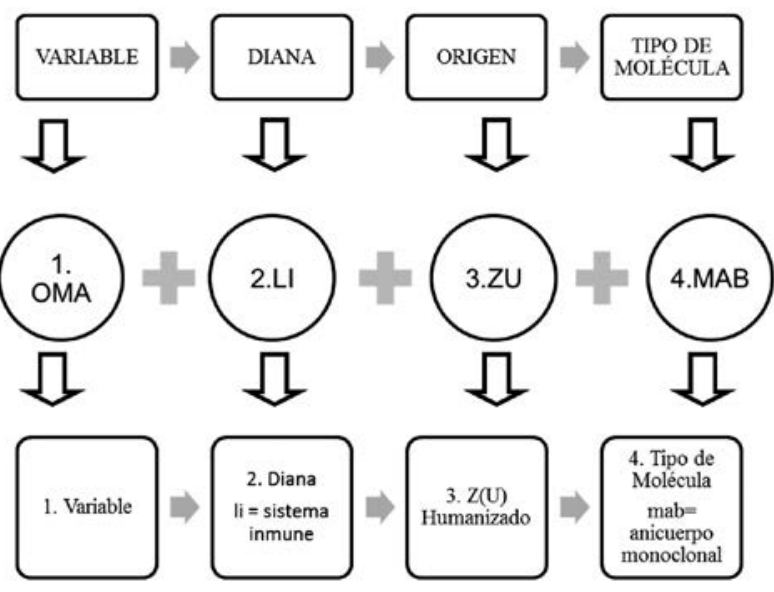

Gráfica 2. Ejemplo de origen medicamento biológico. (9, 10, 13)

\section{Clasificación}

Existen muchas clasificaciones en terapia biológica que buscan facilitar la comprensión de los mecanismos de acción y origen de las moléculas. En la gráfica 3 se describe la clasificación que para los autores representa ser la más práctica:

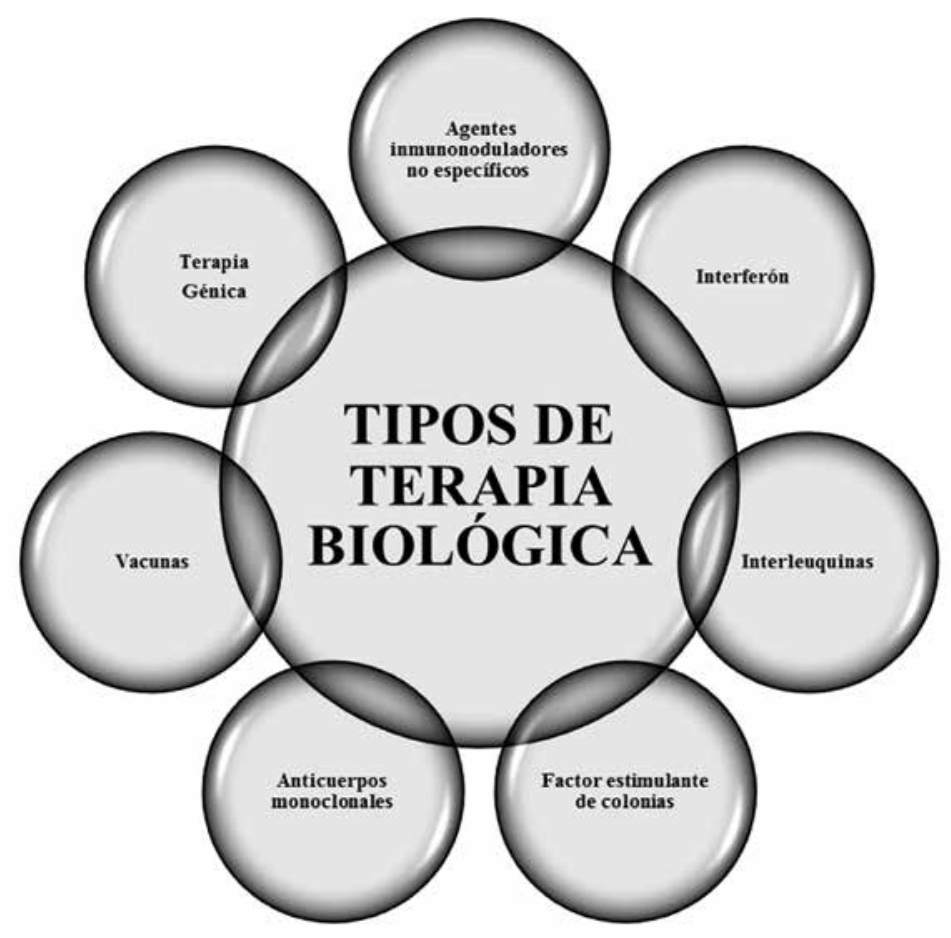

Gráfica 3. Tipos de terapia biológica $(4-7,11,12)$ 
Munar M., Pantoja J., Santacruz J., Villate A., Bastidas A., Giraldo L.

Tabla 2. Clasificación de los medicamentos biológicos (5, 7, 9, 13-15).

\begin{tabular}{|l|l|}
\hline \multicolumn{1}{|c|}{ Grupo biológico } & \multicolumn{1}{c|}{ Ejemplos } \\
\hline Citoquinas & INF alfa, GM-CSF \\
\hline Anticuerpos Monoclonales & \\
\hline 1. Citoquinas & Infliximab (anti-TNF alfa) \\
\hline 2. Moléculas de la membrana celular & Rituximab (anti-CD20) \\
\hline 3. IgE & Omalizumab (anti-IgE) \\
\hline 4. Antígenos tumorales & Cetuximab (anti-EGFR) \\
\hline Proteínas de fusión & \\
\hline 1. Receptor soluble citoquinas & Etarnecept (TNFalfa RII-IgG1) \\
\hline 2. Ligando soluble celular & Abatacept ( CTLA4-IgG1) \\
\hline
\end{tabular}

1. Agentes inmunomoduladores no específicos: Son sustancias que se encargan de estimular el sistema inmunológico, activando células que desencadenarán una respuesta inmunológica secundaria aumentando la producción de citoquinas en inmunoglobulinas. Dentro de este grupo de agentes encontramos el Bacilo Calmette Guerin y el levamisol.

2. Interferón: Los interferones son citoquinas o proteínas, que se producen en el cuerpo en respuesta a una noxa, se encargan de modificar la respuesta biológica. Existen tres tipos principales de interferones: el interferon alfa, beta y gamma. Estos agentes impiden la replicación de células infectadas, además activan células asesinas naturales, linfocitos $\mathrm{T}$ y macrófagos, los cuales se encargan de la destrucción de estas células. Los interferones son agentes que han sido utilizados como complementos en radioterapia y quimioterapia para ciertos tipos de cáncer, infecciones por hepatitis $\mathrm{B}$ y $\mathrm{C}$, esclerosis múltiple y shock séptico.

3. Interleuquinas: Son proteínas que se encargan de coordinar varias funciones celulares, algunas de ellas son: crecimiento celular, inmunidad, diferenciación tisular e inflamación. Las interleuquinas son las encargadas de iniciar la respuesta inflamatoria y de definir la magnitud y naturaleza de la respuesta inmune innata, así como también cumplen un papel fundamental en el desencadenamiento de la respuesta Th1 o Th2 $(1,4,5,7,11,12,16-18)$.
4. Factor estimulante de colonias: el objetivo principal es la estimulación de la medula ósea, para la producción de nuevas células a partir de células madre. Muchos esquemas de tratamiento antitumoral deprimen la producción celular de la medula ósea, aumentando la predisposición a infecciones, sangrado y anemia. La generación de estos nuevos medicamentos que estimula las colonias celulares a partir de células pluripotenciales, permiten que los tratamientos citotoxicos puedan ser utilizados con mayor tranquilidad. Los más utilizados son:

El G-CSF (Filgastrim) y el GM-CSF (Sargramostim) encargados de aumentar el número de leucocitos, reducir el riesgo de infecciones, y estimular la producción de células madre como preparación para transplantes de médula ósea. La Eritropoyetina (Epoiten) aumenta el número de glóbulos rojos y reduce la necesidad de transfusiones.

La Interleukina-11 (Oprelvekin) estimula la producción plaquetas y disminuye la necesidad de transfusión de estos hemoderivados.

Anticuerpos monoclonales: éstos son producidos a partir de una célula híbrida, producto de la fusión entre un clon de linfocito B y una célula plasmática tumoral. Son útiles en el manejo del cáncer, enfermedades autoinmunes, fenómenos de rechazo de trasplantes de órganos, entre otros. En la tabla 3, se describen los diferentes tipos de anticuerpos según su origen y el mecanismo de acción $(4,5,7,11,12,16)$. 


\begin{tabular}{|l|l|}
\hline \multicolumn{1}{|c|}{$\begin{array}{c}\text { Tipo anticuerpo } \\
\text { monoclonal }\end{array}$} & \multicolumn{1}{c|}{ Mecanismo de acción } \\
\hline Murino & $\begin{array}{l}\text { Bloquea la interacción entre el } \\
\text { receptor y el ligando. }\end{array}$ \\
\hline Quimérico & $\begin{array}{l}\text { Activación del complemento por } \\
\text { lisis celular. }\end{array}$ \\
\hline Humanizado & $\begin{array}{l}\text { Lisis celular mediada } \\
\text { por anticuerpos. }\end{array}$ \\
\hline Humano & Vehículos. \\
\hline
\end{tabular}

Tabla 3. Tipo de anticuerpo monoclonal y mecanismo de acción $(5,13,19)$.

Vacunas: La terapia biológica, mediante vacunas, se utiliza en fases de remisión o cuando existe un tumor irresecable. Su utilización se basa en tres enfoques $(4,5$, $7,8,11,12,16)$.
Terapia biológica adoptiva: con esta terapia hay una transferencia de inmunocompetencia entre individuos diferentes.

Terapia biológica pasiva: consiste en la administración de anticuerpos monoclonales.

Terapia biológica activa: se busca la estimulación de componentes clave del sistema inmunitario responsables de la respuesta antitumoral, ésto puede llevarse a cabo mediante la inmunización activa especifica que corresponde a la administración de vacunas o mediante la inmunización activa inespecífica con interferones, IL-2 y la BCG $(7,8,18,20)$.

De acuerdo a lo anterior la terapia biológica con vacunas puede clasificarse de acuerdo a la capacidad de respuesta inmunológica por el antígeno tumoral como observamos en la grafica 4 :

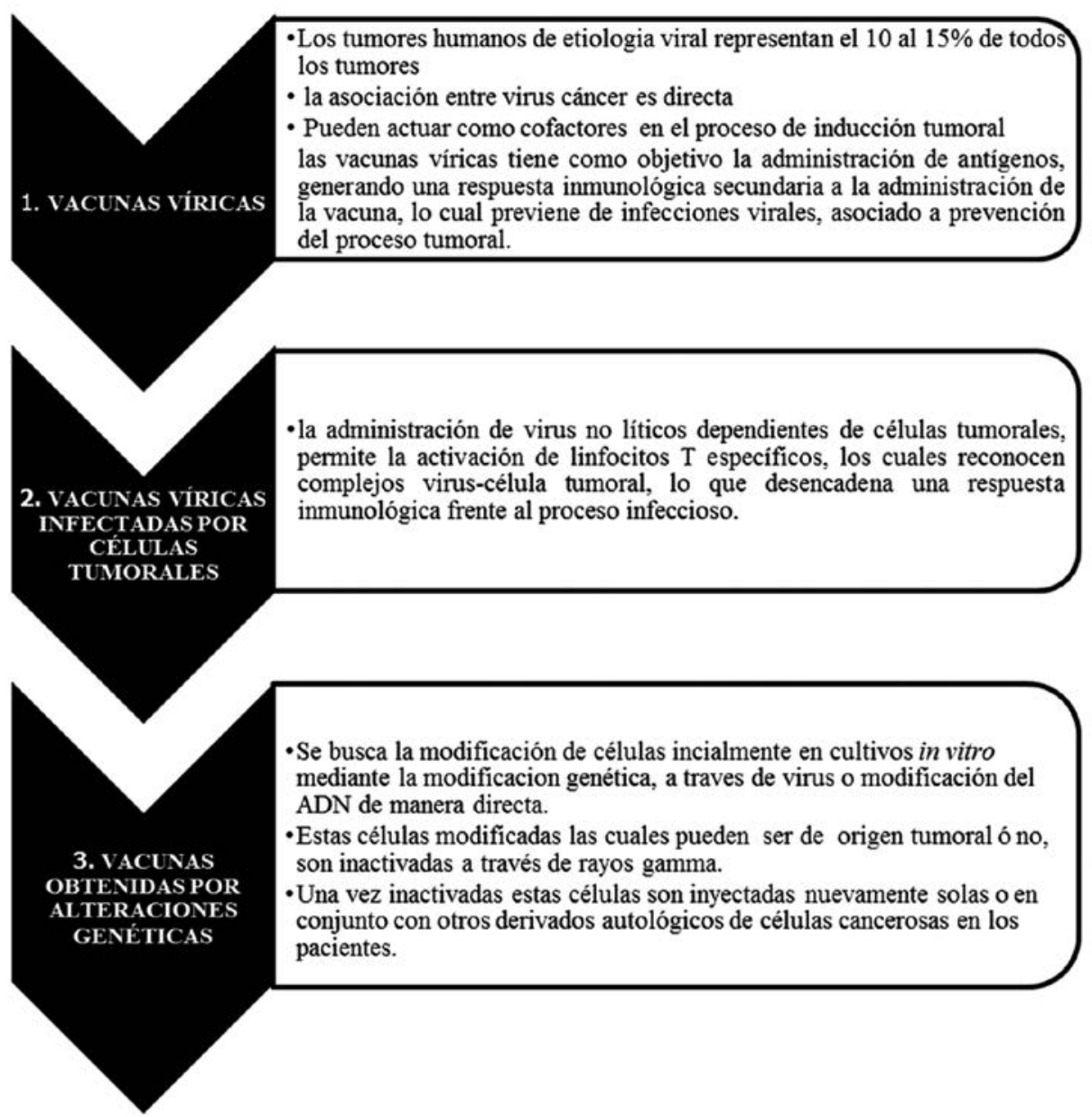

Figura 4. Vacunas en terapia biológica (4, 5, 7, 8, 11, 12, 16, 20). 
Terapia génica: La terapia génica busca crear tratamientos antitumorales más eficaces, mediante material genético que intenta modular las funciones celulares, para así corregir la deficiencia causada por la pérdida o alteración de un gen, esto se logra mediante la modificación en la expresión de proteínas. Existen dos estrategias de tratamiento en la terapia génica, la primera es la estrategia ex vivo, donde las células diana son extraídas y reimplantadas del mismo paciente, después de haber sido modificadas en el laboratorio. Y en la estrategia in vivo, se administra un gen corrector al paciente. Para elegir la mejor estrategia a utilizar, se debe tener en cuenta el origen de la célula blanco y la finalidad del tratamiento. La corrección de las alteraciones génicas pueden ir desde un defecto específico de una población celular, hasta un defecto en la producción celular. El número de enfermedades estudiadas mediante la aplicación de terapia génica ha ido en aumento, se han descrito beneficios y protocolos con esta terapia, para enfermedades hereditarias y enfermedades adquiridas como observamos en la siguiente tabla:

\section{Asma}

El Asma en un $90 \%$ de los casos es una reacción de hipersensibilidad tipo 1 , donde existe una respuesta alérgica provocada por re-exposición a un tipo específico de antígeno, causando que las células plasmáticas secreten de una forma descontrolada $\operatorname{IgE}(33,34)$.

Esta clase de anticuerpos se unen a los receptores para la porción constante $(\mathrm{Fc})$ del anticuerpo sobre la superficie de los mastocitos tisulares y basófilos circulantes, que al cubrirse con IgE son sensibilizados al momento de la aparición inicial del alergeno. Con subsecuentes exposiciones al mismo alergeno, hace que las $\mathrm{IgE}$ se entrecrucen en la superficie celular de células sensibilizadas, resultando en una desgranulación y secreción de mediadores farmacológicamente activos, tales como la histamina, leucotrienos y prostaglandinas. Los principales efectos de estos productos son la vasodilatación y la contracción del músculo liso (33, 35-37).

\begin{tabular}{|c|c|c|c|}
\hline \multicolumn{4}{|c|}{ Enfermedades hereditarias } \\
\hline Enfermedad & Gen suministrado & Tejido diana & Vector \\
\hline Enfisema Pulmonar & Alfa 1- antitripsina & Tracto respiratorio & liposomas \\
\hline Fibrosis quística & CFTR & Tracto respiratorio & $\begin{array}{l}\text { Adenovirus } \\
\text { AAV }\end{array}$ \\
\hline Hipercolesterolemia familiar & Receptor LMW de lipoproteínas & Hepatocitos & Liposomas \\
\hline $\begin{array}{l}\text { Inmunodeficiencia combinada grave } \\
\text { (niño burbuja) }\end{array}$ & Adenosina deaminasa & $\begin{array}{l}\text { Linfocitos } \\
\text { Células pluropotenciales- } \\
\text { hematopoyeticas }\end{array}$ & retrovirus \\
\hline \multicolumn{4}{|c|}{ Enfermedades adquiridas } \\
\hline Enfermedad & Gen suministrado & Tejido diana & Vector \\
\hline SIDA (infección por VIH) & $\begin{array}{l}\text { Ribozomas } \\
\text { ARN antisentido } \\
\text { Anticuerpos }\end{array}$ & Linfocitos & Retrovirus \\
\hline Restenosis (Arterias periféricas) & Factor tumoral de angiogénesis & Células endoteliales & Plásmidos \\
\hline Cáncer & $\begin{array}{l}\text { Genes supresores de tumores } \\
\text { HTK, Ganciclovir } \\
\text { Factor de necrosis tumoral } \\
\text { Interferón (gamma) }\end{array}$ & $\begin{array}{l}\text { Pulmón } \\
\text { Hígado } \\
\text { Cerebro } \\
\text { TIL } \\
\text { Melanoma }\end{array}$ & $\begin{array}{l}\text { Retrovirus } \\
\text { Adenovirus } \\
\text { Retrovirus } \\
\text { Retrovirus } \\
\text { Retrovirus }\end{array}$ \\
\hline
\end{tabular}

Tabla 4. Protocolos de terapia génica aprobados en Estados Unidos (21). 
En el restante $10 \%$, corresponde a una respuesta inflamatoria celular de tipo Th1, donde en TNFa es la piedra angular que desencadena la respuesta inflamatoria de la vía aérea.

A pesar de los múltiples factores que están involucrados en la fisiopatología de la enfermedad, se busca con la terapia actual basada en corticosteroides, antileucotrienos y antihistamínicos, disminuir la respuesta inflamatoria de la vía aérea $(38,39)$. No obstante, estos medicamentos no están exentos de efectos adversos serios y no todos los pacientes se controlan de manera adecuada con esta terapia. Por tal motivo, se han trazado nuevas alternativas en el horizonte, para el tratamiento del asma. El uso de la terapia biológica como moduladores de citoquinas o anticuerpos monoclonales recombinantes humanizados, son actualmente una nueva herramienta terapéutica, que busca principalmente un mayor control de la enfermedad y disminuir los efectos adversos de los medicamentos.

\section{Anti IgE}

Se ha desarrollado un medicamento Anti-IgE, denominado rhumab-E25 (Omalizumab), el cual cuenta con evidencia científica que demuestra su eficacia frente a esta enfermedad (33, 34, 40). Desde el año 2003 la FDA y en el 2005 la Agencia Europea de Medicamentos, aprobaron el Omalizumab, como un anticuerpo monoclonal recombinante humanizado anti IgE para el tratamiento del asma alérgica (41). Recomendando su utilización únicamente para pacientes con asma severa persistente de origen alérgico, prueba cutánea positiva o reactividad in vitro a un alérgeno, pacientes mayores de 12 años, con frecuentes exacerbaciones severas y falta de respuesta a los medicamentos habitualmente utilizados en esta enfermedad.

El principio de este medicamento, es ligarse a la IgE circulante en el mismo epítope de la región Fc que se une a FcrRI, formando complejos inmunes, disminuyendo de esta manera sus niveles en el plasma en cerca de un $89-99 \%$. Por lo tanto, entre mayores concentraciones de IgE sérica, se observa una mejor respuesta al medicamento $(33,34)$. Como se liga al mismo epítope, significa que el Omalizumab no es anafilactogénico, puesto que no puede interactuar con la IgE que ya esta unida a las superficies de las células, bloqueando la degranulación de basófilos y mastocitos e impidiendo de esta manera que se desencadene la respuesta anafiláctica $(33,34,40)$
Existen ya varios ensayos clínicos (fase I, II y III) con poblaciones de niños y adultos, que respaldan el uso del Omalizumab, como una nueva alternativa de manejo para pacientes con diagnóstico confirmado de asma alérgica severa $(42,43)$. Estos estudios demuestran un beneficio clínico, con el uso del Omalizumab vs placebo y/o uso de corticosteroides, evidenciado en disminución de las exacerbaciones y disminución en la dosis de corticosteroides inhalados para el control de las crisis e impactando en la calidad de vida de los pacientes (40,44-47). No obstante el control y la eficacia del mismo, tambien depende de la vigilancia de los factores ambientales y condiciones coexistentes en el paciente asmático.

Este medicamento, que en Colombia cuenta con registro sanitario del INVIMA desde el 2005, se administra como una solución de polvo blanco, liofilizado, estéril, sin conservantes, que se debe reconstituir con agua para preparaciones inyectables. Se aplica como una inyección subcutánea cada 2 ó 4 semanas, usualmente en la región deltoidea del brazo o en el muslo (48). La dosis a administrar se debe calcular individualmente para cada paciente, teniendo en cuenta los niveles de IgE sérica, antes de iniciar el tratamiento, y el peso corporal del paciente, pera esto se deben tener e cuenta las tablas arrojadas por los estudios que respaldan el uso del medicamento. En la actualidad, la tabla de dosificación para Omalizumab se basa en una dosis máxima de $750 \mathrm{mg}$ cada 4 semanas, pues la eficacia del tratamiento con niveles de IgE por encima de 700 $\mathrm{UI} / \mathrm{ml}$, se encuentra en estudio $(40,47)$.

Finalmente, la evaluación de la respuesta a la terapia con Omalizumab, se basa en la evaluación global del médico (entrevistas con los pacientes, revisión de la evolución medica, la espirometría y verificación de los síntomas diarios, el uso de medicación de rescate y el flujo espiratorio máximo), a la semana 16 de iniciar el tratamiento, se ha determinado cual es la medida más significativa de la identificación de respuesta al medicamento.

Se recomienda hacer a la semana 16 , teniendo en cuenta que es un período coherente con el mecanismo de acción del medicamento y la aparición progresiva de su acción visto en los ensayos clínicos que lo respaldan. Estudios multicéntricos, doble ciego, aleatorizados, controlados con placebo, fase III han demostrado que la respuesta a Omalizumab se ha caracterizado por un inicio gradual, con un $38 \%$ de los pacientes que 
responden a las 4 semanas de iniciar el tratamiento, en comparación con el $64 \%$ a la semana 16 . De estos, sólo el $61 \%$ había respondido a las 4 semanas, el $78 \%$ había respondido a las 8 semanas y el $87 \%$ había respondido a las 12 semanas. Teniendo en cuenta que se rotulaban como respondedores a la terapia, los pacientes sin exacerbaciones y uno o más de los siguientes: reducción de los síntomas, uso reducido de fármacos de rescate, mejoría de la función pulmonar y una mejor calidad de vida.

Sin embargo, se ha observado que los pacientes que requieren corticosteroides orales diarios para el control del asma, pueden tener una menor respuesta al tratamiento con Omalizumab.

Por lo tanto, el Omalizumab esta indicado como 5 línea de manejo del Asma alérgica severa persistente. Observándose en los ensayos clínicos una reducción significativa de la exacerbación del asma y las tasas de visita a los servicios de urgencias, mejorando significativamente la calidad de vida en pacientes (33, $34,40,44-46)$.

\section{Modulador de citoquinas TNFa}

En el marco de la terapia biológica para manejo del asma, se ha desarrollado otra línea de tratamiento, teniendo en cuenta el papel de las citoquinas como proteínas de bajo peso molecular esenciales para comunicación intercelular y desarrollo de la enfermedad (35). Por tal motivo, el TNF- $\alpha$ es fundamental para el proceso que conduce al asma y en particular, al desarrollo de la limitación del flujo aéreo persistente y la hiperreactividad bronquial en pacientes con asma refractaria, a pesar del uso de altas dosis de corticosteroides (49).

En este campo se ha propuesto el uso de 2 moléculas para el tratamiento de la enfermedad, un inhibidor del factor de necrosis tumoral conocido como etanercept, medicamento de administración subcutánea, con una vida media entre 70 y 120 horas, el cual está compuesto por 2 partes, una de ellas es una porción de la inmunoglobulina humana y la otra es un receptor del factor de necrosis tumoral (TFN). Este medicamento, se une específicamente al factor de necrosis tumoral, lo bloquea $e$ inhibe de esta forma los mecanismos bioquímicos que provocan la respuesta inflamatoria, mejorando los síntomas de la enfermedad. Teniendo como base teórica, el papel crítico que cumple el TNF- $\alpha$ a través de efectos autocrinos y paracrinos, en la iniciación y la amplificación de la inflamación de las vías respiratorias y la remodelación de la misma que sufren los pacientes con Asma mediada por una respuesta inmunológica Th1 (49-52).

Ensayos clínicos con diseño doble ciego, cruzados y controlados con placebo, han evaluado el tratamiento con etanercept a dosis de $25 \mathrm{mg} 2$ veces a la semana. Los resultados obtenidos muestran que los pacientes con asma refractaria tienen una sobre-expresión del eje del TNF- $\alpha$, y que al tratarse con este medicamento presentan una mejoría en la calidad de vida, relacionada con el asma y un incremento de alrededor de $300 \mathrm{ml}$ en el VEF1 pos-broncodilatador, al compararse con los que no lo recibieron. $Y$ en terapias que se extienden de las 10 a las 12 semanas en pacientes con asma moderada, se incrementa la cantidad de metacolina necesaria para una caída del $20 \%$ del volumen espiratorio forzado en el primer segundo. Sin embargo, se debe tener en consideración que al inhibir el eje de TNFa, se desajustan los niveles de defensa del cuerpo y puede generar predisposición a infecciones frecuentes (53). El segundo fármaco es el Infliximab, un anticuerpo monoclonal quimérico humano derivado de ratón, que se une con alta afinidad tanto a la forma soluble como a la de transmembrana del TNF alfa, disminuyendo así su acción proinflamatoria y mejorando los síntomas de la enfermedad. Sin embargo, los estudios que hasta ahora se conocen, no han incluido un paciente con asma severa. Finalmente en lo que se tiene de literatura, la falta de eficacia del infliximab asociado a su alto costo, se repite en la mayoria de conclusiones. De igual forma, se debe aclarar que es necesario realizar todavía estudios grandes, multicéntricos, aleatorizados, controlados con placebo, en pacientes con asma crónica grave (54).

\section{IL-5}

Se ha propuesto también el papel de la IL-5, tambien conocida como factor quimiotáctico de eosinófilos, como un protagonista de la cascada inflamatoria en la vía Th2. Por tal motivo, se han creado agentes como el Mepolizumab, un anticuerpo monoclonal humanizado contra la interleuquina-5, como tratamiento de gran importancia en pacientes que cursan específicamente con asma eosinofílica, debido a que su mecanismo de acción lleva a una inhibición selectiva y eficaz de este tipo de inflamación mediado por eosinófilos y los productos de su degranulación. 
Estudios tipo ensayo clínico con significancia estadística, arrojan que el uso de Mepolizumab se asoció significativamente con un menor número de exacerbaciones graves comparado con placebo, asociado a una reducción significativa del recuento de eosinófilos en la sangre, logrando impactar positivamente en la calidad de vida en sujetos con asma eosinofílica refractaria y un historial de exacerbaciones recurrentes (55).

\section{Enfermedad Pulmonar Obstructiva Crónica (EPOC)}

La enfermedad pulmonar obstructiva crónica se encuentra asociada a una respuesta inflamatoria anormal del pulmón a una noxa (principalmente cigarrillo), este proceso inflamatorio lleva a una obstrucción del flujo de aire parcialmente reversible, secundaria a una remodelación de la vía aérea pequeña, con pérdida del retroceso elástico por destrucción enfisematosa del parénquima pulmonar $(56,57)$.

El proceso inflamatorio es el resultado del daño inducido por la exposición crónica al humo y/o a otros agentes tóxicos, que llevan finalmente a la infiltración de células inflamatorias en la mucosa, submucosa y tejido glandular generando hipersecreción de moco, hiperplasia de células endoteliales y remodelamiento tisular de la vía aérea (56), además la producción exagerada de proteasas lleva finalmente a la destrucción del propio parénquima pulmonar generando aéreas de enfisema. Este proceso es mediado por macrófagos, neutrófilos y la activación principalmente de una respuesta inmune TH1 $(57,58)$.

Los diferentes tipos de agentes nocivos producen inicialmente un daño directo en las células epiteliales de la vía aérea. Se produce una activación de receptores de patrones de reconocimiento a señales de daño, por radicales de oxigeno ( $\mathrm{ROS}$ ), receptores de patrones moleculares asociados a daño (DAMPs) y receptores de patrones comunes moleculares asociado a patógeno (PAMPs). Las señales producidas por los mismos son reconocidas por receptores toll like TLR 2 y TLR 4, presentes en células epiteliales que desencadenan una respuesta inflamatoria no específica (59).

Hay liberación temprana de citoquinas (TNFa, interleucinas 1,6 y 8, proteína 1 alfa inflamatoria de macrófagos, leucotrieno B4) con migración de macrófagos, neutrofilos y células dendríticas que inician una respuesta inmune. Adicionalmente se liberan por estas células, enzimas proteolíticas (elastasa de neutrofilos, metaloproteasas (metaloproteasa 9, serin proteasas y trombina que activa receptores PAR1 y TGF-B) y radicales de oxigeno, que si no encuentran un balance con antiproteasas o factores antioxidantes desencadenan mayor daño tisular (60).

Las células dendríticas toman autoantigenos liberados por daño tisular y los presentan a células T nativas en nódulos linfoides con activación de linfocitos T CD4, linfocitos $\mathrm{B}$ y principalmente de linfocitos T CD8, que viajan al tejido pulmonar a neutralizar estos antígenos. Secundario al daño generado por las propias células del huésped, se inicia un proceso de reparación no regulado que involucra el factor transformador de crecimiento B (TGF-b), con activación de fibroblastos y miofibroblastos que llevan a fibrosis $(59,60)$.

En el tratamiento actual se utilizan broncodilatadores beta 2 agonistas, anticolinérgicos inhalados, teofilina y oxigeno que limitan y mejoran los síntomas, sin embargo, no hay una mejoría significativa de la función pulmonar en los pacientes con EPOC (56-58). Según la fisiopatología de la enfermedad se plantea diferentes blancos para el desarrollo de nuevos medicamentos (61), dirigidos principalmente a disminuir la inflamación, la fibrosis, la proteólisis y la producción de moco $(57,58,62)$.

\section{Derivados de la inhibición de las fosfodiesterasas}

Con la utilización de fármacos que inhiben las fosfodiesterasas y la observación de una disminución de la respuesta inflamatoria y del número de exacerbaciones en pacientes con EPOC severo, se ha desarrollado el Tetomilast, su función biológica es inhibir de manera potente la producción de citoquinas y superoxido de los neutrófilos y su adhesión, adicionalmente disminuye la actividad de la fosfodiesterasa 4 (58).

\section{Anti-TNF}

Se han propuesto inhibidores de TNF como agentes para inducir remisión de la enfermedad en pacientes con enfermedades inflamatorias crónicas, resistentes al manejo, como por ejemplo el Infliximab y Etanercept (63). La terapia con Infliximab en pacientes con enfermedad pulmonar obstructiva crónica, no ha tenido buenos resultados (64), en el momento se encuentra en estudio el RDP - 58, un decapéptido activo oral- 
mente (con potencial para tratamiento inhalado) (58), inhibidor de la transducción de RNAm de TNF y que puede tener un efecto benéfico en la terapia biológica para EPOC.

\section{Inhibidores selectivos del fosfoinositol 13 kinasa delta (PI13Kd)}

En EPOC se cree que por estrés oxidativo existe una disminución en la sensibilidad a glucocorticoides, lo cual se relaciona con una disminución en la actividad de la deacetilasa de histona 2 y un aumento en la señalización por fosfoinositol 3 quinasa delta $\delta$, que se encuentra elevada en los macrófagos de pacientes con EPOC (65). Se encuentran en estudio nuevas moléculas encargadas de inhibir selectivamente el PI13Kd, permitiendo restaurar la sensibilidad a corticoides en monocitos de estos pacientes (66).

\section{Medicamentos mucoactivos}

Adicionalmente se han creado medicamentos mucoactivos, para tratar la hipersecreción de moco dirigido contra receptor tirosin quinasa EGF y bloqueador de canales de calcio activados por cloro (66-68).
En el gráfico 5 se muestran los posibles blancos para el desarrollo de terapia biológica en EPOC. Muchos de estos medicamentos se encuentran en desarrollo y fases de investigación inicial, por lo que no existen resultados al momento en el control de los síntomas y disminución en la progresión de la enfermedad (56$58,61,69)$.

\section{Enfermedad pulmonar parenquimatosa intersticial}

Este término agrupa una serie de patologías, que se caracterizan por presentar un curso de inflamación crónica irreversible, que la mayoría de las veces lleva a fibrosis. La neumonía intersticial usual, enfermedad representativa de este grupo de patologías, se caracteriza por falla en la reepitelización alveolar con proliferación de fibroblastos y miofibroblastos, que aumentan el depósito de matriz extracelular, conllevando finalmente a fibrosis y distorsión de la arquitectura pulmonar (70, 71). El desencadenante de esta respuesta inflamatoria crónica no se ha identificado por completo, se ha propuesto el contacto con agentes infecciosos, factores exposicionales, entre otros. Sin embargo, se reconoce que este proceso inflamatorio puede ser cíclico y que

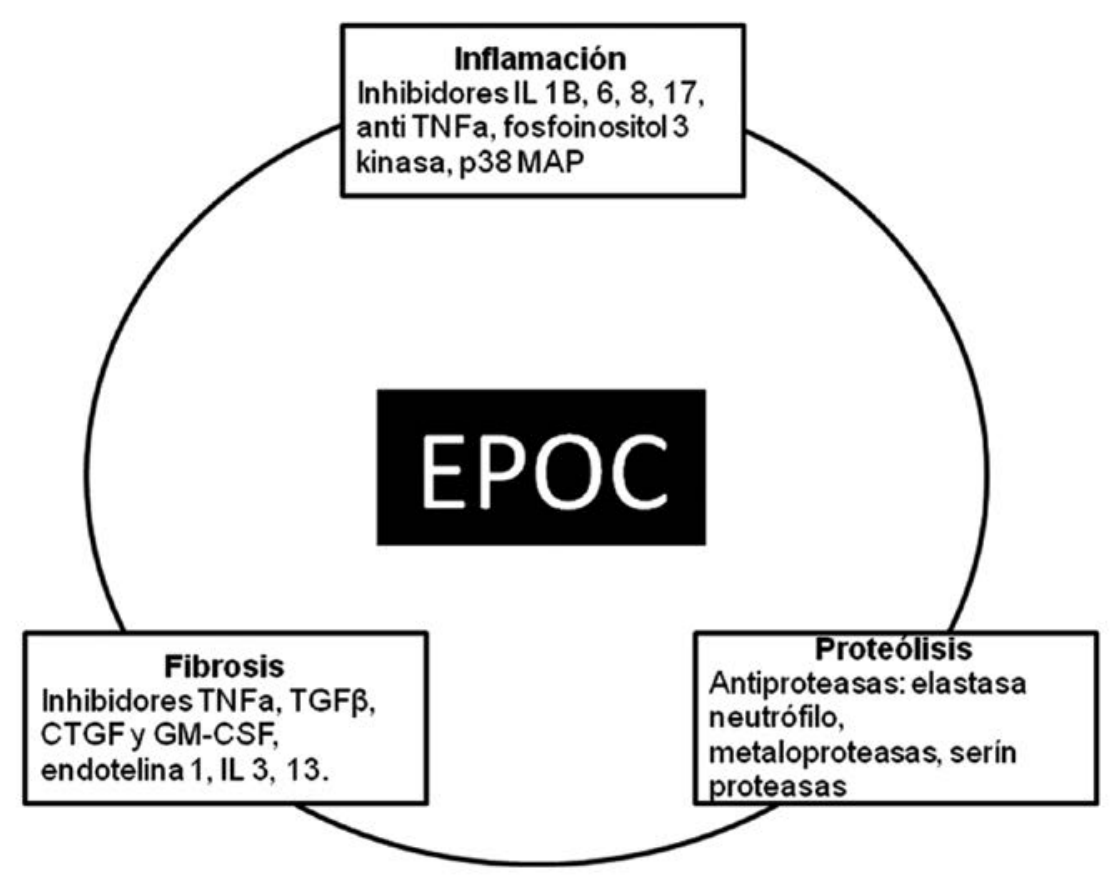

Gráfica 5. Blancos de terapia biológica en EPOC. 


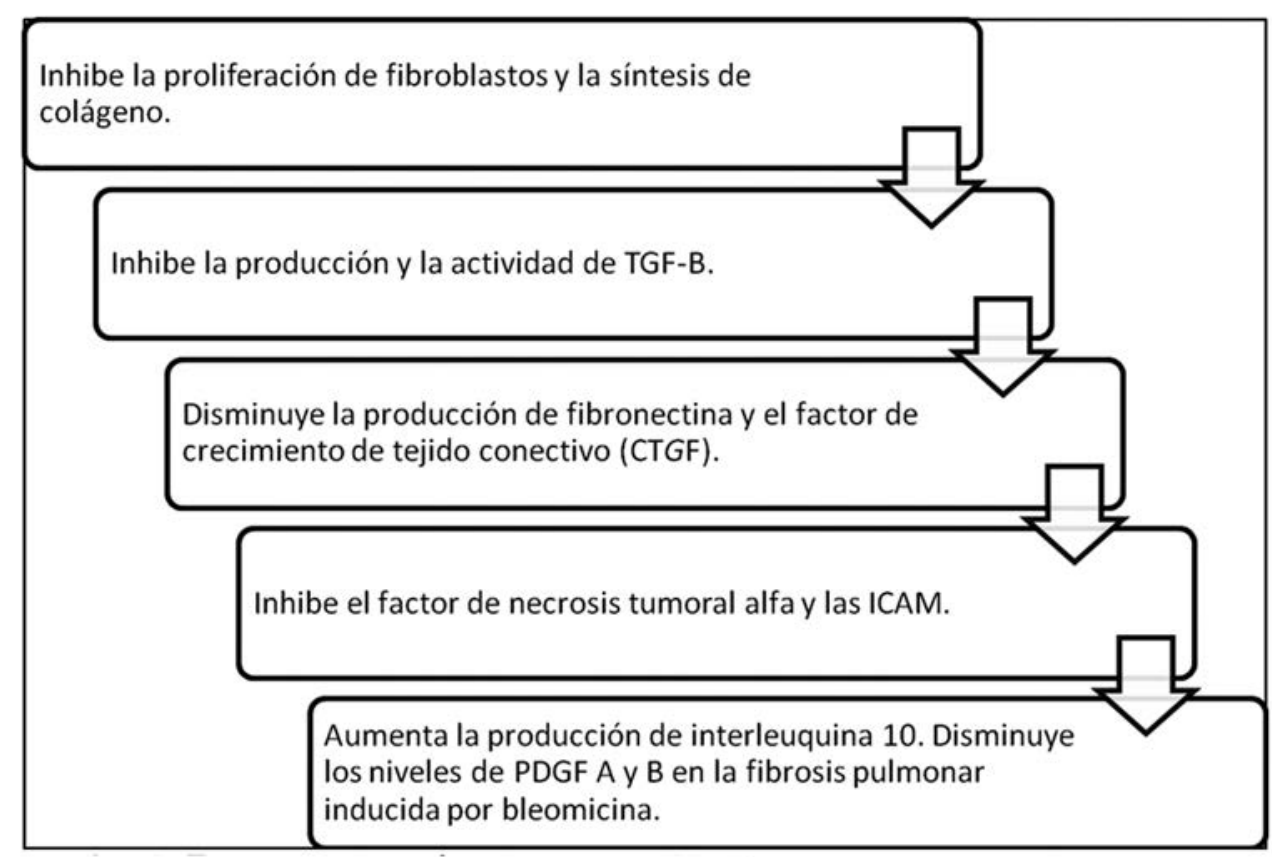

Gráfica 6. Esquema de acciones del Pirfenidone.

actúan en el curso de la enfermedad y proliferación celular mediadores como el factor de crecimiento transformador B1 (TGF-b), el factor de crecimiento de tejido conectivo, así como factores de angiogénesis, citocinas inflamatorias y estrés oxidativo $(73,74)$.

En plan de interrumpir la cascada inflamatoria y de que ocurra una lesión tisular irreversible con fibrosis, se han utilizado corticoides, terapia citotóxica y antiinflamatoria (ciclofosfamida, azatioprina, colchicina, D-penicilamina) (71,72). Sin embargo, no se han obtenido buenos resultados buscando nuevos blancos terapéuticos, teniendo en la cuenta la fisiopatogenia inflamatoria de la enfermedad $(74,75)$.

\section{Antifibróticos y antiinflamatorios}

En este grupo de medicamentos se ha desarrollado el Pirfernidone, el cual actúa como un inhibidor de la peroxidación de lípidos y reduce la sobreexpresión del RNAm de colagenasas inducida por el TGF-b y otras citoquinas. En el momento, con su utilización hay una disminución de la progresión histológica de la enfermedad y mejoría de la función pulmonar, no obstante, aún no se ha demostrado de manera significativa mejoría en la sobrevida (75-77). En la gráfica número 6 se esquematiza de manera mas especifica las acciones del Pirfenidone.

\section{Interferón}

El interferón gamma disminuye la expresión de factor de crecimiento transformador $\mathrm{B}$, implicado en la proliferación de fibroblastos y deposito de colágeno. Un estudio mostró, que con su uso subcutáneo a 12 meses, se obtenía una mejoría en volúmenes pulmonares, intercambio gaseoso y alivio de síntomas (78). Posteriormente, 2 estudios clínicos —randomizados, controlados y con placebo- mostraron eficacia con esta intervención, sin embargo, no se logró mostrar ningún beneficio en los desenlaces primarios, ni secundarios (79). Un metanálisis reciente publicado en Cochrane falló en demostrar efectos clínicamente significativos en cuanto a mortalidad, progresión de la enfermedad o en la función pulmonar (80). Debido a ésto, las últimas guías en el manejo de fibrosis pulmonar dan una advertencia en contra de su uso para el tratamiento de esta patología, dejando de ser una opción terapéutica en este tipo de pacientes $(72,75)$.

\section{Anticuerpos monoclonales}

Se han propuesto anticuerpos monoclonales contra TGF e inhibidores del receptor quinasa de TGF-b, los cuales inhiben la inducción de fibrosis y bloquean la fibrosis progresiva (81). El Infliximab se ha estudiado en pacientes con artritis reumatoidea y enfermedades 
Tabla 5. Vías blanco para terapia.

\begin{tabular}{|l|l|}
\hline \multicolumn{2}{|c|}{ Vías blanco para terapia } \\
\hline Céulas epiteliales alveolares & $\begin{array}{l}\text { Anticuerpos anti-idiotipicos reconocen los com- } \\
\text { plejos y la localización del antígeno anticuerpo y } \\
\text { son capaces de imitar su estructura y función. }\end{array}$ \\
\hline $\begin{array}{l}\text { Inhibidores migración y proliferación de } \\
\text { fibroblastos / miofibroblastos }\end{array}$ & $\begin{array}{l}\text { Zileuton, análogos prostaglandinas, pirfenidona, } \\
\text { ARA II, estatinas (induce apoptosis). }\end{array}$ \\
\hline Angiogénesis & $\begin{array}{l}\text { Quimiocinas angioestáticas, IFN gamma 1b - } \\
\text { tetratiomolybdate. }\end{array}$ \\
\hline Balance citocinas Th1/Th2 & IFN gamma 1b, anti IL4, anti IL13. \\
\hline Stress oxidativo & $\begin{array}{l}\text { Oligonucleósidos NF-kB, inhibidores óxido } \\
\text { nítrico sintetasa. }\end{array}$ \\
\hline
\end{tabular}

de colágeno con fibrosis pulmonar, sin mostrar cambios en la función pulmonar, sin embargo, en los pacientes que iniciaron esta terapia no mostró deterioro de los síntomas respiratorios ni imagenológico (82). Otros medicamentos como el Etanercept no han mostrado reducción en la enfermedad pulmonar intersticial asociada a enfermedades del colágeno.

Paradójicamente la utilización de anticuerpos monoclonales, como el tocilizumab utilizado en artritis reumatoidea, se ha asociado a fibrosis pulmonar sin poderse establecer hasta el momento causalidad $(83,84)$. En la tabla 5 se resumen los posibles blancos terapéuticos en enfermedad pulmonar parenquimatosa difusa.

\section{Cáncer pulmonar}

En el crecimiento, desarrollo y diferenciación de células tumorales se han encontrado en los últimos años una gran variedad de vías de señalización molecular. Estos hallazgos han permitido el diseño de nuevos agentes terapéuticos para el control o la disminución de la progresión de este tipo de enfermedad (85).

La terapia biológica, en desarrollo para combatir el cáncer pulmonar, busca mediante el conocimiento fisiopatológico de las vías moleculares, disminuir la tasa de crecimiento celular, potenciar el sistema inmune en el reconocimiento de células anormales, aumentar la capacidad de destrucción tumoral, así como activar vías que mejoren la capacidad de regeneración de células normales, modificar las células tumorales y disminuir el potencial metastásico (85-88).
Actualmente encontramos tres grupos de medicamentos biológicos que hasta el momento han sido aprobados como esquemas de tratamiento del cáncer (gráfico 7):

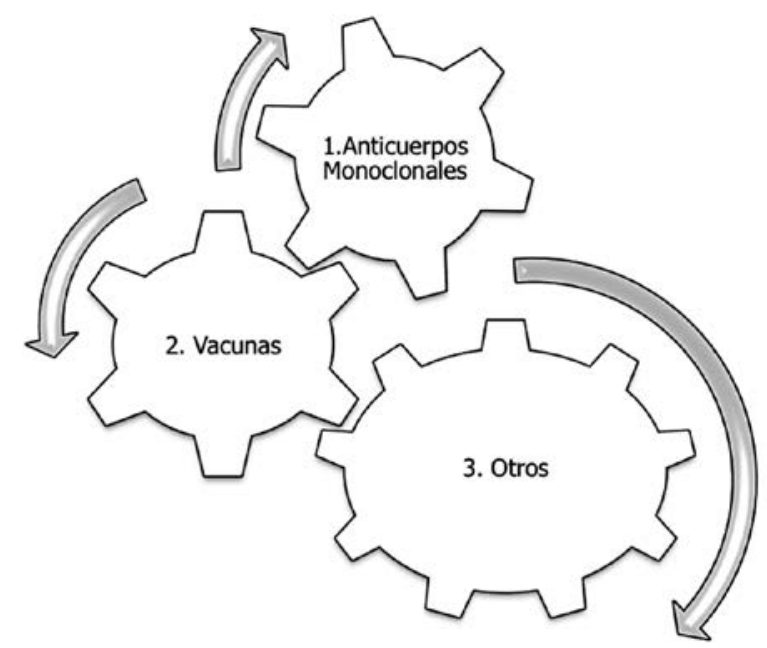

Gráfica 7. Opciones terapéuticas para cáncer pulmonar.

\section{Anticuerpos monoclonales}

Los anticuerpos circulantes se producen en respuesta a una noxa, se definen como una proteína pegajosa la cual se dirige frente a un antígeno especifico. Cuando se obtiene la unión antígeno- anticuerpo se activan una serie de vías moleculares que identifican las moléculas antigénicas destruyendo aquellas células tumorales que las contengan. En la gráfica 8 se mencionan las principales tipos de anticuerpos monoclonales aprobados por la FDA, como agentes terapéuticos frente al cáncer $(89,90)$. 


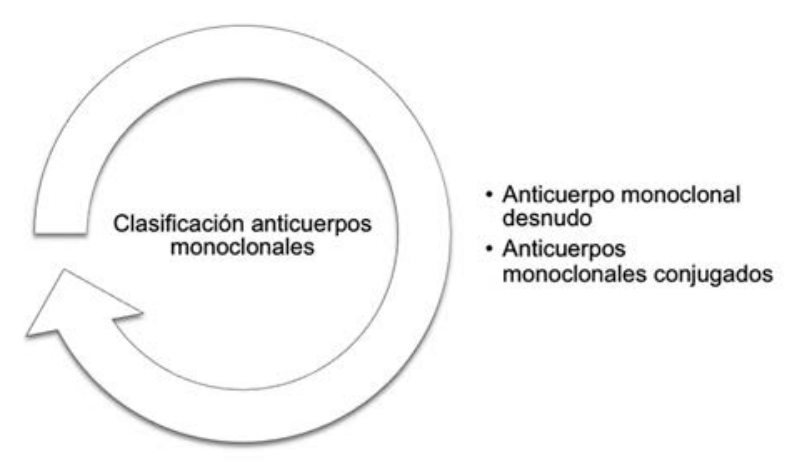

Gráfica 8. Clasificación de los anticuerpos monoclonales (89-91).

\section{Anticuerpo monoclonal desnudo}

El principal blanco de estos agentes es unirse a un antígeno o célula cancerosa específica y de esta manera amplificar la respuesta inmune, dañando la estructura celular de células cancerosas lo que finalmente llevara a la inhibición de proteínas especificas en los procesos de señalización y crecimiento tumoral.

\section{Anticuerpos monoclonales conjugados}

Este tipo de anticuerpos se encuentran unidos a un fármaco o toxina radiactiva, estas sustancias son inyectadas a las células cancerosas para posteriormente ser rastreadas por dispositivos. Dentro de este grupo de agentes terapéuticos existen subgrupos: en el primero, partículas radioactivas se unen a los anticuerpos lo que se conoce como radioinmunoterapia. El segundo subgrupo contempla los fármacos quimioterapéuticos unidos al anticuerpo los cuales se conocen como quimioconjugados, en el tercero se encuentran aquellas toxinas celulares que se unen a anticuerpos conocidas como inmunotoxinas (89-94).

Tabla 6. Tipos de anticuerpos monoclonales conjugados (91-96)

\begin{tabular}{|l|l|l|}
\hline Radioinmunoterapia & \multicolumn{1}{|c|}{ Quimioconjugados } & \multicolumn{1}{|c|}{ Inmunotoxinas } \\
\hline $\begin{array}{l}\text { Son anticuerpos } \\
\text { radiomarcados } \\
\text { con pequeñas } \\
\text { partículas } \\
\text { radioactivas }\end{array}$ & $\begin{array}{l}\text { Son anticuerpos } \\
\text { unidos a potentes } \\
\text { fármacos utilizados } \\
\text { para quimioterapia, } \\
\text { esta unión } \\
\text { disminuye las } \\
\text { reacciones adversas } \\
\text { de la monoterapia }\end{array}$ & $\begin{array}{l}\text { Son agentes en } \\
\text { estudio los cuales } \\
\text { utilizan sustancias } \\
\text { tóxica des- } \\
\text { truir células cance- } \\
\text { rosas específicas }\end{array}$ \\
\hline
\end{tabular}

\section{Anticuerpos monoclonales en cáncer pulmonar}

En el cáncer de pulmón el manejo actual basado en cirugía, radioterapia y quimioterapia, no ha mostrado resultados satisfactorios, buscando así, con el desarrollo y diseño de anticuerpos monoclonales, mayores tasas en el control de síntomas y de supervivencia. Hasta el momento, los estudios con este tipo de medicamentos que han mostrado resultados alentadores, han sido estudiados dentro los esquemas de tratamiento habitual, sin existir recomendaciones para su utilización como monoterapia (94).

Los anticuerpos monoclonales tienen una eficacia mayor sobre una carga tumoral limitada, de esta manera se garantiza un entorno adecuado como terapia adyuvante, obteniendo de esta manera las mayores tasas de éxito para erradicar el potencial metastásico, destruir las células residuales cancerosas y retrasar los procesos de crecimiento y progresión tumoral $(91,97,98)$.

\begin{tabular}{|l|l|}
\hline \multicolumn{1}{|c|}{ Inmunoterapia pasiva } & \multicolumn{1}{c|}{ Inmunoterapia activa } \\
\hline Anticuerpos dirigidos contra & $\begin{array}{l}\text { Anticuerpos anti-idiotipicos } \\
\text { reconocen los complejos y la }\end{array}$ \\
las células tumorales. & $\begin{array}{l}\text { Anticuerpos dirigidos contra } \\
\text { factores de crecimiento y } \\
\text { proliferación del antígeno anti- } \\
\text { cuerpo y son capaces de imitar } \\
\text { Eu estructura y función. }\end{array}$ \\
$\begin{array}{l}\text { Anticuerpos contra meca- } \\
\text { nismos de escape de células } \\
\text { tumorales. }\end{array}$ & \\
Terapia combinada inmunote- \\
rapia pasiva más anticuerpos \\
monoclonales.
\end{tabular}

\begin{tabular}{|l|l|}
\hline \multicolumn{1}{|c|}{$\begin{array}{c}\text { Anticuerpos } \\
\text { inmunoconjugados }\end{array}$} & Otros usos de anticuerpos \\
\hline $\begin{array}{l}\text { Inmunotoxinas } \\
\text { Radionmunoterapia } \\
\text { Quimioconjugados }\end{array}$ & $\begin{array}{l}\text { Prefármacos. } \\
\text { Activación de células T } \\
\text { Redirección de células T con } \\
\text { anticuerpos dirigidos contra } \\
\text { dichas células } \\
\text { Fragmentos de anticuerpo } \\
\text { Radioinmunocirugía } \\
\text { Técnicas de ablación inmuno- } \\
\text { guiadas }\end{array}$ \\
\hline
\end{tabular}

Tabla 7. Principales anticuerpos monoclonales descritos en la terapia de cáncer pulmonar (91- 98). 
La inmunoterapia pasiva, en el momento, no ha mostrado superioridad sobre los actuales esquemas de tratamiento para el cáncer de pulmón, sin embargo, nuevas investigaciones en este campo han dirigido sus blancos hacia un anticuerpo conocido como fucosil gangliosido GM-1, el cual disminuye la capacidad metastásica del cáncer de pulmón.
Por otra parte los anticuerpos monoclonales dirigidos contra el factor de crecimiento epidérmico como el Cetuximab, se han considerado agentes terapéuticos de primera línea, por aumentar la tasa de supervivencia, reconociéndose la reacción de eritema en piel como uno de sus efectos adversos más significativos (99-101).

\begin{tabular}{|c|c|c|}
\hline Antígeno & Nombre del antígeno & Tipos de tumor \\
\hline \multirow{5}{*}{$\begin{array}{l}\text { Diferenciación de antígenos } \\
\text { hematopoyéticos. }\end{array}$} & CD19, CD20, CD22, CD25. & Linfoma de células $\mathrm{B}$. \\
\hline & HLA DR. & Linfoma de células $\mathrm{B}$. \\
\hline & CD30. & Linfoma de hodgkin. \\
\hline & CD33, CD45. & Leucemia linfoide aguda. \\
\hline & CD52. & Desórdenes linfoides (células B y celuas T). \\
\hline \multirow{21}{*}{$\begin{array}{l}\text { Diferenciación de antígenos de la } \\
\text { superficie celular. }\end{array}$} & \multicolumn{2}{|c|}{ Glicoproteínas } \\
\hline & Antígeno Carconoembrionario. & Tumores epiteliales. \\
\hline & $\begin{array}{l}\text { Glicoproteínas asociados a tumores } \\
\text { (TAG72). }\end{array}$ & Tumores epiteliales (seno, pulmón y colon). \\
\hline & $\begin{array}{l}\text { Moléculas de adhesión de células } \\
\text { epiteliales. }\end{array}$ & Tumores epiteliales (seno, pulmón y colon). \\
\hline & Mucina epitelial polimórfica. & Tumores epiteliales (seno, pulmón y colon). \\
\hline & A33 & Cáncer colorectal. \\
\hline & G250 & Carcinoma renal de células claras. \\
\hline & Antígeno prostático especifico. & Carcinoma de Próstata. \\
\hline & \multicolumn{2}{|c|}{ Glicolipidos } \\
\hline & Gangliosidos (GD2, GD3, GM2). & Tumores neuroectodermicos. \\
\hline & \multicolumn{2}{|c|}{ Carbohidratos } \\
\hline & Antígeno Y Lewis. & Tumores epiteliales (seno, pulmón y colon). \\
\hline & Antígeno cáncer 125 & Carcinoma de Ovario. \\
\hline & Antígeno cáncer 19.9 & Tumores epiteliales. \\
\hline & \multicolumn{2}{|c|}{ Receptores de Factor de crecimiento } \\
\hline & $\begin{array}{l}\text { EGFR (CETUXIMAB) aprobado } \\
\text { FDA en } 2004 .\end{array}$ & $\begin{array}{l}\text { Tumores de cabeza y cuello, pulmón, seno y } \\
\text { cáncer colorectal. }\end{array}$ \\
\hline & $\begin{array}{l}\text { Mutación de EGFR (delección de } \\
\text { exones 2-7). }\end{array}$ & $\begin{array}{l}\text { Gliobloastoma multiforme, seno y cáncer de } \\
\text { pulmón. }\end{array}$ \\
\hline & HER2/NEU. & $\begin{array}{l}\text { Cáncer de seno, pulmón y carcinoma de } \\
\text { próstata. }\end{array}$ \\
\hline & \multicolumn{2}{|c|}{ Antígenos del estroma y la angiogénesis } \\
\hline & $\begin{array}{l}\text { Proteínas activadoras de } \\
\text { fibroblastos. }\end{array}$ & Tumores epiteliales. \\
\hline & $\begin{array}{l}\text { Receptor de crecimiento vascular } \\
\text { endotelial. }\end{array}$ & Tumores vasculares. \\
\hline
\end{tabular}

Tabla 8. Antígenos tumorales que son reconocidos por los anticuerpos monoclonales y su uso clínico $(97,102,103)$. 


\section{Vacunación}

Se han adelantado un buen numero de estudios con el ánimo de encontrar una salida definitiva a este gran grupo de entidades oncológicas, sin embargo, hasta el momento el panorama no es muy alentador, teniendo solo un estudio con resultados oficiales y concretos de Fase III, sin muy buenos resultados. A continuación, exponemos las vacunas más relevantes en las cuales se ha trabajado:

\section{BEC2 y BCG}

El BEC2 es un anticuerpo de monoclonal de origen murino anti-idiotípicos que imita a los gangliósidos GD3, expresados en la superficie de las células tumorales en el cáncer de pulmón de células pequeñas de enfermedad limitada (SCLC). Este anticuerpo monoclonal se utiliza en conjunción con el bacilo de Calmette-Guerin (BCG), para lograr montar una respuesta inmune contra GD3 endógena. Esta es la única vacuna contra el cáncer pulmonar que ha sido evaluada en estudios completos de fase III. Lamentablemente este estudio no confirmo el beneficio clínico propuesto por estudios de fases iniciales I y II, donde se veía que pacientes con cáncer pulmonar de células pequeñas en estadios I y II, con respuesta importante a la radiación de la quimioterapia, recibieron la vacuna y desarrollaron anticuerpos anti-GD3 significando una mayor supervivencia en comparación con los controles.

La conclusión del estudio fue frustrante, pues la vacuna fue bien tolerada, pero en comparación con el grupo control, no hubo mejoría en la supervivencia, ni supervivencia libre de progresión.

\section{GVAX, Allo GVAX, y Lucanix}

Tal vez, es una de las iniciativas mas conocidas de este campo. Inicialmente se propuso como vacuna experimental autóloga de células tumorales con un importante efecto en el cáncer pulmonar de células no pequeñas, ayudando al sistema inmune a atacar células cancerosas y a bloquear la diseminación durante un tiempo prolongado. En el primer estudio fase I/II, se encontró que un porcentaje de los pacientes experimentaron una recuperación completa y sin recaídas durante un periodo de 3 años. Por lo tanto, sugería una correlación positiva entre la producción de GM-CSF por la vacuna y la respuesta clínica.
Seguido a este, se realizó un segundo estudio "AlloGVAX", con la premisa de tener una alta secreción de GM-CSF a nivel constante. Para esto, se propuso un transplante celular autólogo de cáncer pulmonar de célula no pequeña (NSCLC), asociado a una línea celular alogénica GM-CSF secretor (células K562). Sin embargo, a la aplicación del estudio Fase I/II de prueba para esta nueva vacuna, si bien, se documento una aumento significativo en los niveles de la secreción de GM-CSF, no se obtuvo una respuesta objetiva en la génesis tumoral de los pacientes observados.

Lucanix es la última propuesta realizada por el mismo grupo de los anteriores estudios, donde se propone una vacuna compuesta de cuatro líneas de células alogénicas de CPNM transducidas con factor de crecimiento transformante-b antisentido. En 2008, el grupo inició un estudio fase III controlado con placebo de Lucanix en estadio III y IV de CPNM, los resultados finales del estudio no se han publicado, por lo cual la comunidad científica se encuentra a la expectativa de los mismos.

\section{BLP25 (Stimuvax)}

Esta vacuna tiene como principio para su acción, una glicoproteína de membrana denominada la mucina 1 (MUC1), que juega un papel fundamental en la progresión tumoral. Siendo en esencia un antígeno propio, la vacuna está sobreexpresada y alterada en carcinomas e induce respuestas inmunes a ella, esta se asocia con varios factores de transcripción promoviendo genes que codifican proteínas implicadas en señales proliferativas y pro-supervivencia.

Por lo tanto, la vacuna BLP25 de liposomas (L-BLP25) lleva la proteína mucina-1 (MUC1) mezclado con monofosforil lípido A, como un coadyuvante inmunológico, teniendo como punto de acción estratégico esta glicoproteína, buscando de esta manera bloquear la proliferación celular y la génesis de el carcinoma.

Se han realizado estudios clínicos fase IIb para esta vacuna, en pacientes con NSCLC con respuesta o enfermedad estable después de una terapia de primera línea. Al analizar los datos, no se encontró diferencia estadísticamente significativa en la supervivencia global, pero una tendencia en la supervivencia media en un subgrupo de pacientes. Teniendo como base los resultados anteriores, se realizó un estudio fase III, controlada con placebo del cual todavía no se tienen resultados finales certeros. $(85,104-105)$. 


\section{Inmunoterapia no específica}

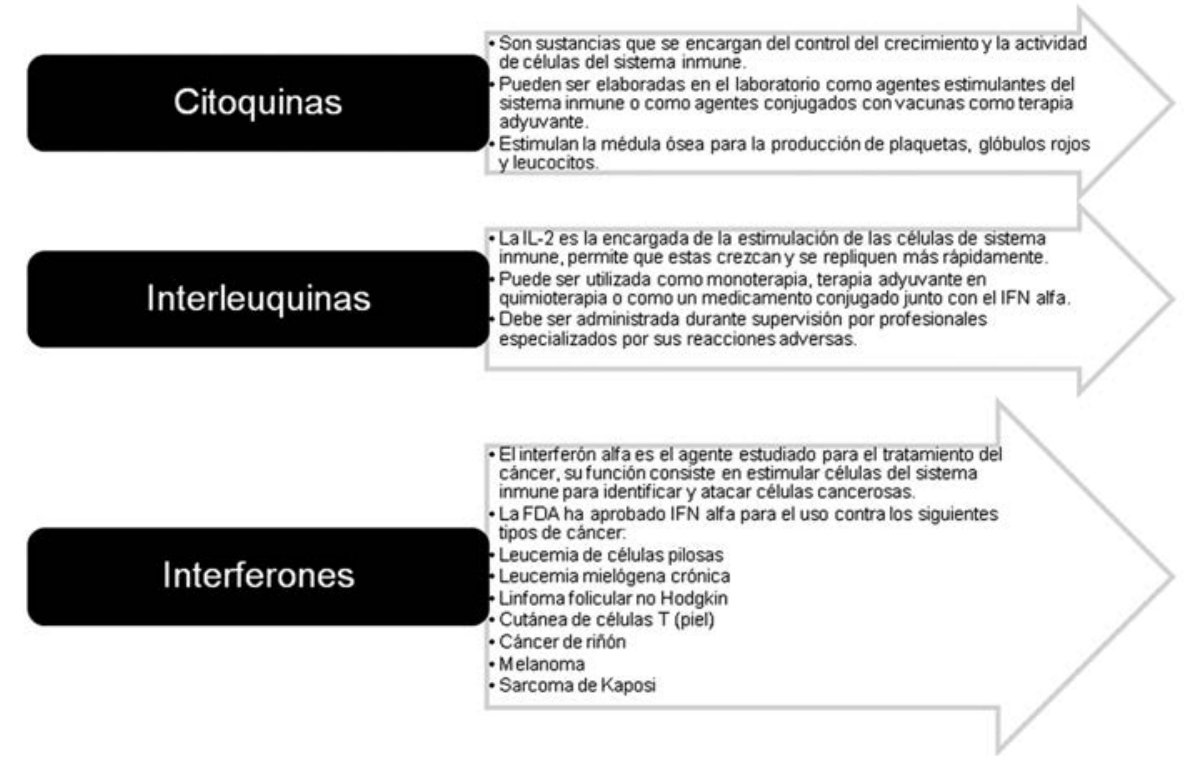

Gráfica 9. Inmunoterapia no específica en cáncer pulmonar (90).

\section{Discusión}

La terapia biológica, resultado de los avances de la biología molecular y la ingeniería genética, ofrece una alternativa nueva para el tratamiento de las enfermedades pulmonares (1-8), a través, de la producción de nuevos medicamentos que actúan en nuevos blancos terapéuticos (13-15).

El uso de terapia biológica para el manejo del asma, tiene la mayor evidencia en literatura científica, las recomendaciones, indicaciones y manejo, se encuentran plenamente identificadas en guías mundialmente aceptadas (33), convirtiendose en una alternativa ideal para pacientes con asma severa con respuesta de hipersensibilidad tipo I (34), mostrando buenos resultados posteriores al uso (40, $42-43)$.

En la enfermedad pulmonar obstructiva crónica, la terapia biológica se ha enfocado en disminuir la inflamación, la fibrosis, la proteólisis y la producción de moco, sin embargo, no existen resultados concluyentes requiriéndose el desarrollo de mas estudios para verificar la utilidad de la terapia biológica en estos puntos, de modo similar, en la enfermedad pulmonar parenquimatosa difusa, la evidencia es limitada, la poca prevalencia de esta enfermedad y la evolución clínica variable son obstáculos para evaluar la utilidad y efectividad de este tipo de terapia, siendo necesario el desarrollo de estudios con muestras poblacionales grandes (57-62).

La terapia biológica en cáncer de pulmón esta enfocada en la inhibición de la génesis tumoral, el crecimiento y la diferenciación celular, convirtiéndose en una opción importante como terapia coadyuvante para los esquemas de tratamiento actual (85-88), y ofrece en este campo, las mejores perspectivas de desarrollo para el manejo de la enfermedad (89-90).

\section{Conclusiones}

La terapia biológica ofrece nuevas alternativas para el tratamiento de enfermedades pulmonares crónicas, como el asma, coadyuvancia en cáncer de pulmón, pero son necesarios más estudios para probar efectividad en enfermedad pulmonar obstructiva crónica y enfermedad pulmonar intersticial difusa. 


\section{Referencias}

1. Abbas AK, Lichtman AH. Cellular and molecular immunology. 6th edition. Philadelphia: Saunders; 2009. Acceso Marzo 9, 2010.

2. Biological Therapy; Disponible en: http://www.ncbi.nlm.nih. gov/mesh?term = biological\%20therapy

3. FDA consumer Health Information/U.S Food and Drug Administration. July 25 2008. Disponible en: www.fda.gov/ consumer/updates/biologics062608.html

4. Biological Therapies for Cancer, 13 de Junio de 2006, National Cancer Institute. Disponible en: http://www.cancer. gov/clinicaltrials/

5. EMA Cfmpfhuc-. Guideline on similar biological medicinal products. 2005 [28.04.2011]; Disponible en: http://www.ema. europa.eu/docs/en_GB/document_library/Scientific_guideline/2009/09/WC5000

6. Waldmann T. Mechanisms of immunotherapy. Nature medicine. 2003; (9) 269- 277.

7. The Leukemia \& Lymphoma Society. Emerging Therapies in Leukemia, Lymphoma \& Myeloma. Transcripción de teleconferencia. Disponible en: www.leukemia lymphoma.org/ all_page?item_id $=557011$

8. Fry TJ, Lankester AC. Cancer Immunotherapy: Will Expanding Knowledge Lead to Success in Pediatric Oncology?. Hematol Oncol Clin N Am. 2010; 24; 109-127.

9. Eichbaum C, Haefeli WE. Nomenklatur und Einteilung von Biologicals. Therapeutische Umschau. 2011; 68(11) 593-601.

10. Villa, J. Uso de agentes biológicos en reumatología. Fundación Española de Reumatología: Hospital de Sierrallana. Disponible en: http://www.hospitalsierrallana.com/uploads/ Uso_agentes_biologicos_Reumatologia.pdf

11. Agustín O. Terapias Biológicas en pediatría actualización. Noviembre de 2009. Nomenclatura; página 5. Disponible en: http://auditoriamedicahoy.net/biblioteca/TERAPIAS\%20 BIOLOGICAS.\%20ACTUALIZACION.pdf

12. Campos L, Carroz M, Dell Acqua M, Mendieta M, Milanese P, Viera P. Terapias Biológicas, conceptos generales y participación en el esquema de costos global de medicamentos. Disponible en: http://auditoriamedicahoy.net/biblioteca/ Terapiasbiol\%C3\%B3gicas.pdf

13. Horton SC. Biological therapy for rheumatoid arthritis: where are we now? British Journal of Hospital Medicine. 2012; 73 (1) $12-8$.

14. Hausmann OV, Seitz M, Villiger PM, Pichler WJ. The Complex Clinical Picture of Side Effects to Biologicals. Med Clin N Am. 2010; 94: 791-804.

15. Pichler WJ. Adverse side effects to biological agents. Allergy. 2006; 61(8): 912-20.

16. AMA. Naming Guidelines: Rules for Coining Names: Naming Biologics. 2011 [04.05.2011]; Disponible en: http://www. ama-assn.org/ama/pub/physician-resources/medicalscience/united-states-adopted-names-council/naming-guidelines/ naming-biologics.page?

17. Abbas AK, Murphy KM, Sher A. Functional diversity of helper T lymphocytes. Nature. 1996; 383(6603): 787-93.

18. Akdis CA, Blaser K. Mechanisms of allergen-specific immunotherapy. Allergy. 2000; 55: 522-530.

19. Lutterotti A, Roland M. Getting specific: monoclonal antibodies in multiple sclerosis. Lancet Neurology. 2008; 7: 538-47.

20. Han SJ, Gurvinder K, Yang I, Lim M. Biologic Principles of Immunotherapy for Malignant Gliomas. Neurosurg Clin N Am. 2010; 21: 1-16.
21. Rosalén J, Fernandez F, Ceña V, Jordán J. Aplicaciones de la Terapia Génica. OFFARM. 2003; 22(10) 142-150.

22. Lees CW, Ali AI, Thompson AI, et al. The safety profile of antitumour necrosis factor therapy in inflammatory bowel disease in clinical practice: analysis of 620 patient-years follow-up. Aliment Pharmacol Ther. 2009; 29(3): 286-97.

23. Krause I, Valesini G, Scrivo R, et al. Autoimmune aspects of cytokine and anticytokine therapies. Am J Med. 2003; 115(5): 390-7.

24. Mazurek J, Jahnz-Różyk K. The variety of types of adverse side-effects during treatment with biological drugs. Int. Rev. Allergol. Clin. Immunol. Family Med. 2012; 18(1) 34-39.

25. Pichler WJ. Delayed drug hypersensitivity reactions. Ann Intern Med. 2003; 139: 683-693.

26. Kassiotis G, Kollias G. TNF and receptors in organ-specific autoimmune disease: multi-layered functioning mirrored in animal models. J Clin Invest. 2001:107:1507-1508.

27. Taylor A, Verhagen J, Akdis CA, Akdis M. T regulatory cells in allergy and health: a question of allergen specificity and balance. Int Arch Allergy Immunol. 2004; 135: 73-82.

28. Weiner L. Fuly human therapeutic monoclonal antibodies. Journal of immunotherapy. 2006; 29(1); 1-9.

29. Schirrmacher V. Tumor vaccine design: concepts, mechanisms and efficacy testing. Int Arch Allerg Immunol. 1995; 108: 340-4.

30. Weiner LM. Fully human therapeutic monoclonal antibodies. J Immunother. 2006; 29(1); 1-9.

31. Olsen NJ, Stein CM. New drugs for rheumatoid arthritis. N Engl J Med. 2004; 350(21): 2167-2179.

32. Till SJ, James F, Kayhan NA, Durham S. Mechanisms of immunotherapy. The Journal of Allergy and Clinical Immunology. 2004; 113 (6): 1025-1034

33. Busse W, Corren J, Lanier BQ, et al. Omalizumab, anti-IgE recombinant humanized monoclonal antibody, for the treatment of severe allergic asthma. J Allergy Clin Immunol. 2001; 108: 184-90.

34. Bousquet J, Rabe K, Humbert M, et al. Predicting and evaluating response to omalizumab in patients with severe allergic asthma. Respir Med. 2007; 101: 1483-92.

35. Holgate ST. Cytokine and anti-cytokine therapy for the treatment of asthma and allergic disease. Cytokine. 2004; 28:152-157.

36. Catley MC, Coote J, Bari M, Tomlinson KL. Monoclonal antibodies for the treatment of asthma. Pharmacology \& Therapeutics. 2011; 132: 333-351.

37. D'Amato G. Role of anti-IgE monoclonal antibody (omalizumab) in the treatment of bronchial asthma and allergic respiratory diseases. European Journal of Pharmacology. 2006; 533: 302-307.

38. Adams RJ, Fuhlbrigge A, Guilbert T, Lozano P, Martinez F. Inadequate use of asthma medication in the United States: results of the asthma in America national population survey. J Allergy Clin Immunol. 2002; 110: 58-64.

39. Weiss K, Sullivan S. The health economics of asthma and rhinitis. Assessing the economic impact. J Allergy Clin Immunol. 2001; 107: 3-8.

40. Humbert M, Beasley R, Ayres J, Slavin R, Hebert J, Bousquet $\mathrm{J}$, Beeh KM, et al. Benefits of omalizumab as add-on therapy in patients with severe persistent asthma who are inadequately controlled despite best available therapy (GINA 2002 step 4 treatment): INNOVATE. Allergy. 2005; 60: 309-316.

41. Lang DM, Kavuru MS. Omalizumab: Where does it fit into current asthma management? Cleveland Clinic Journal of Medicine. 2004; 71(3): 251-261.

42. Milgrom $\mathrm{H}$, Berger W, Nayak A, et al. Treatment of childhood asthma with antiimmunoglobulin E antibody (omalizumab). Pediatrics. 2001; 108: 36. 
43. Walker S, Monteil M, Phelan K, Lasserson TJ, Walters EH. Anti-IgE for chronic asthma in adults and children. Cochrane Database Syst Rev. 2006; 19(2): CD003559.

44. Soler M, Matz J, Townley R, et al. The anti-IgE antibody omalizumab reduces exacerbations and steroid requirement in allergic asthmatics. Eur Respir J. 2001; 18: 254-61.

45. Soler M, Matz J, Townley R, Buhl R, O'Brien J, Fox H, Thirlwell J, et al. The anti-IgE antibody omalizumab reduces exacerbations and steroid requirement in allergic asthmatics. Eur Respir J. 2001; 18: 254-261.

46. Bousquet J, Cabrera P, Berkman N, Buhl R, Holgate S, Wenzel $\mathrm{S}$, et al. The effect of treatment with omalizumab, an anti-IgE antibody, on asthma exacerbations and emergency medical visits in patients with severe persistent asthma. Allergy. 2005; 60: 302-308.

47. Ayres JG, Higgins B, Chilvers ER, Ayre G, Blogg M, Fox H. Efficacy and tolerability of anti-immunoglobulin $E$ therapy with omalizumab in patients with poorly controlled (moderate-tosevere) allergic asthma. Allergy. 2004; 59: 701-708.

48. República de Colombia. Ministerio de la Protección Social. Instituto Nacional de Vigilancia de Medicamentos y Alimentos - INVIMA. Resolución No. 2005013247 del 26 de junio del 2005, Por la cual se concede un Registro Sanitario.

49. Mauad T, Bel EH, Sterk PJ. Asthma therapy and airway remodeling. J Allergy Clin Immunol. 2007; 120(5): 997-1009.

50. Erin EM, Leaker BR, Nicholson GC, Tan AJ, Green LM, Neighbour $\mathrm{H}$, et al. The effects of a monoclonal antibody directed against tumor necrosis factor- $\alpha$ in asthma. Am J Respir Crit Care Med. 2006; 174: 753-762.

51. Berry MA, Hargadon B, Shelley M, Parker D, Shaw DE, Green $\mathrm{RH}$, et al. Evidence of a role of tumor necrosis factor alpha in refractory asthma. N Engl J Med. 2006; 354: 697-708.

52. Howarth PH, Babu KS, Arshad HS, Lau L, Buckley M, McConnell W, et al. Tumour necrosis factor (TNFalpha) as a novel therapeutic target in symptomatic corticosteroid dependent asthma. Thorax. 2005; 60: 1012-1018.

53. Guilleminault L, Carré Ph, Beau-Salinas F, Taillé C, Dieudé $\mathrm{Ph}$, Crestani B, et al. Asthma Unmasked With Tumor Necrosis Factor - a - Blocking Drugs. Chest. 2011; 140: 1068-1071.

54. Edwards C, Polosa R. Study of Infliximab Treatment in Asthma. Am. J. Respir. Crit. Care Med. 2007; 175(2): 196.

55. Haldar P, Brightling CE, Hargadon B, Gupta S, Monteiro W, Sousa A, et al. Mepolizumab and Exacerbations of Refractory Eosinophilic Asthma. N Engl J Med. 2009; 360: 973-84.

56. Global strategy for the diagnosis, management and prevention of chronic obstructive pulmonary disease (revised 2011) Disponible en: www.goldcopd.org.

57. Decramer M, Janssens W, Miravitlles M. Chronic obstructive pulmonary disease. Lancet. 2012; 379: 1341-51.

58. Molfino N, Jeffery P. Chronic obstructive pulmonary disease: Histopathology, inflammation and potential therapies. Pulmonary Pharmacology \& Therapeutics. 2007; 20: 462-472.

59. Brusselle G, Joos G, Bracke K. New insights into the immunology of chronic obstructive pulmonary disease. Lancet. 2011; 378: 1015-26.

60. Hanse Tl, Barnes PJ. New drugs for exacerbations of chronic obstructive pulmonary disease. Lancet. 2009; 374: 744-55.

61. Cosío B, Núñez B. Nuevas perspectivas terapéuticas farmacológicas en el manejo de la EPOC. Arch Bronconeumol. 2007; 43(4): 27-35.

62. De Boer W I. Cytokines and Therapy in COPD. A Promising Combination? Chest. 2002; 121: 209S-218S.

63. Aeberli D, Oertle S, Mauron $\mathrm{H}$, et al. Inhibition of the TNFpathway: use of infliximab and etanercept as remission-inducing agents in cases of therapy-resistant chronic inflammatory disorders. Swiss Med Wkly. 2002; 132(29-30): 414-22.

64. Rennard SI, Fogarty C, Kelsen S, Long W, Ramsdell J, Allison $\mathrm{J}$, et al. The safety and efficacy of infliximab in moderate-tosevere chronic obstructive pulmonary disease. Am J Respir Crit Care Med. 2007.175 (9):926-29.

65. Rennard SI, Fogarty C, Kelsen S, Long W, Ramsdell J, Allison $\mathrm{J}$, et al. The safety and efficacy of infliximab in moderate-tosevere chronic obstructive pulmonary disease. Am J Respir Crit Care Med. 2007;175 (9):930-34.

66. Banerjee A, Koziol-White C, Panettieri RJr. p38 MAPK inhibitors, IKK2 inhibitors, and TNFa inhibitors in COPD. Current Opinion in Pharmacology. 2012; 12: 287-292.

67. Barnes PJ. Current and future therapies for airway mucus hypersecretion. Novartis Found Symp. 2002; 248: 237-49.

68. Zheng J-P, Kang J, Huang S-G, et al. Effect of carbocisteine on acute exacerbation of chronic obstructive pulmonary disease (PEACE Study): a randomised placebo-controlled study. Lancet. 2008; 371: 2013-18.

69. Blanchard C, Mishra A, Saito-Akei H, et al. Inhibition of human interleukin-13-induced respiratory and oesophageal inflammation by anti-human-interleukin-13 antibody (CAT354). Clin Exp Allergy. 2005; 35(8): 1096-103.

70. Gross T, Hunninghake G. Idiopathic pulmonary fibrosis. N Engl J Med. 2001; 345(7): 517-525.

71. American Thoracic Society, European Respiratory Society: American Thoracic Society/European Respiratory Society International Multidisciplinary Consensus Classification of the Idiopathic Interstitial Pneumonias. This joint statement of the American Thoracic Society (ATS), and the European Respiratory Society (ERS) was adopted by the ATS board of directors, June 2001 and by the ERS Executive Committee, June 2001. Am J Respir Crit Care Med. 2002; 165(2): 277-304.

72. Raghu G, Collard HR, Egan JJ, et al. An official ATS/ERS/ JRS/ALAT statement: idiopathic pulmonary fibrosis: evidencebased guidelines for diagnosis and management. Am J Respir Crit Care Med. 2011; 183(6): 788-824.

73. Toby M. Idiopathic Pulmonary Fibrosis: Pathobiology of Novel Approaches to Treatment. Clin Chest Med. 2012; 33(1): 69-83.

74. Antoniou KM, Pataka A, Bouros D, Siafakas NM. Pathogenetic pathways and novel pharmacotherapeutic targets in idiopathic pulmonary fibrosis. Pulmonary Pharmacology \& Therapeutics. 2007; 20: 453-461.

75. Cerri S, Spagnolo P, Luppi F, Richeldi L, Management of Idiopathic Pulmonary Fibrosis. Clin Chest Med. 2012; 33: 85-94.

76. Maher TM. Pirfenidone in idiopathic pulmonary fibrosis. Drugs Today (Barc). 2010; 46(7): 473-482.

77. Noble PW, Albera C, Bradford WZ, et al. Pirfenidone in patients with idiopathic pulmonary fibrosis (CAPACITY): two randomised trials. Lancet 377. 2011; (9779): 1760-1769.

78. Ziesche R, Hofbauer E, Wittmann K, Petkov V, Block LH. A Preliminary study of long-term treatment with interferon gamma-1b and low-dose prednisolone in patients with idiopathic pulmonary fibrosis. NEJM. 1999; 341(17): 1264-1269.

79. Raghu G, Brown KK, Bradford WZ, Starko K, Noble PW, Schwartz DA, King TE. A placebo-controlled trial of interferon gamma-1b in patients with idiopathic pulmonary fibrosis. N Engl J Med. 2004; 350(2): 125-133.

80. Spagnolo P, Del Giovane C, Luppi F, Cerri S, Balduzzi S, Walters $\mathrm{EH}$, et al. Non-steroid agents for idiopathic pulmonary fibrosis. Cochrane Database of Systematic Reviews 2010, Issue 9. Art. No.: CD003134. DOI:10.1002/14651858.CD003134.pub2.

81. Richeldi L, Costabel U, Selman M, Soon Kim D, Hansell DM, Nicholson AG, et al. Efficacy of a tyrosine kinase inhibitor 
in idiopathic pulmonary fibrosis. N Engl J Med. 2011; 365: 1079-87.

82. Antoniou KM, Mamoulaki M, Malagari K, Kritikos HD, Bouros D, Siafakas NM, et al. Infliximab therapy in pulmonary fibrosis associated with collagen vascular disease. Clinical and Experimental Rheumatology. 2007; 25: 23-28.

83. Hadjinicolaou AV, Nisar MK, Bhagat S, Parfrey H, Chilvers $\mathrm{ER}$, et al. Non-infectious pulmonary complications of newer biological agents for rheumatic diseases a systematic literature review. Rheumatology (Oxford). 2011; 50(12): 2297-2305.

84. Panopoulos ST, Sfikakis PP. Biological treatments and connective tissue disease associated interstitial lung disease. Current Opinion in Pulmonary Medicine. 2011; 17(5): 362-367.

85. Ming-Yi H, Shye-Jye T, Kuang-Hui S, Winnie Y. Immunotherapy for Lung Cancers. Journal Of Biomedicine \& Biotechnology [doi:10.1155/2011/250860]. (2011, Jan); 1-10.

86. Hirschowitz E, Yannelli J. Immunotherapy for Lung Cancer. Proc Am Thorac Soc. 2009; 6: 224-232,

87. Isobe T, Herbst RS, Onn A. Current management of advanced non-small cell lung cancer: targeted therapy. Semin Oncol. 2005; 32: 315-328.

88. Raez L, Fein S, Podack E. Lung Cancer Immunotherapy. Clinical Medicine \& Research. 2005; 3(4): 221-228.

89. Biological Therapies for Cancer, 13 de Junio de 2006, National Cancer Institute. Disponible en: http://www.cancer.gov/clinicaltrials/

90. American Cancer Society, Immunotherapy 2012. Disponible en: http://www.cancer.org/Search/index?QueryText=immun otherapy\& $x=42 \& y=16$

91. Egria G, Takats A. Monoclonal antibodies in the treatment of lung cancer. The Journal Of Cancer Surgery (EJSO). 2006; 32: 385-394.

92. Kreitman RJ, Pastan I. Immunotoxins for targeted cancer therapy. Adv

93. Drug Deliv Rev. 1998; 31(1-2): 53-88.

94. Henry CJ, Buss MS, Hellstrom I, Hellstrom KE, Brewer WG, Bryan JN, et al. Clinical evaluation of BR96 sFv-PE40 immunotoxin therapy in canine models of spontaneously occurring invasive carcinoma. Clin Cancer Res. 2005; 11(2 Pt 1): 751-5.

95. Lynch Jr TJ, Lambert JM, Coral F, Shefner J, Weu P, Blattler WA. Immunotoxin therapy of small-cell lung cancer: a phase I study of N901-blocked ricin. J Clin Oncol. 1997; 15(2): 723-34.
96. Zimmermann S, Wels W, Froesch BA, Gerstmayer B, Stahel RA, Zangemeister-Wittke U. A novel immunotoxin recognising the epithelial glycoprotein-2 has potent antitumoural activity on chemotherapy-resistant lung cancer. Cancer Immunol Immunother. 1997; 44(1): 1-9.

97. Zeng L, Ge D, Lin S, Ge X, Xhong G, Zhu J. Research on radioimmunotherapy of lung cancer in nude mice using lung cancer monoclonal antibody LC-1 combined with Y-90. Chin J Lung Cancer. 2003; 6(4): 258-60.

98. Harris M. Monoclonal antibodies as therapeutic agents for cancer, Lancet Oncol. 2004; 5: 292-302.

99. Rayzman V, Scott A. Monoclonal antibodies for cancer therapy. Cancer Forum. 2002; 26: 104-08.

100. Kim ES, Mauer AM, Tran HT, Liu D, Gladish G, Dicke K. A phase II study of cetuximab, an epidermal growth factor receptor (EGFR) blocking antibody, in combination with docetaxel in chemotherapy refractory/resistant patients with advanced non-small cell lung cancer: final report. Proc $\mathrm{Am}$ Soc Clin Oncol. 2003; 22: 642a.

101. Lynch TJ, Lilenbaum R, Bonomi P, Ansari R, Govindan R, Janne PA, A phase II trial of cetuximab as therapy for recurrent non-small cell lung cancer (NSCLC). Proc Am Soc Clin Oncol. 2004; 23: 634a.

102. Rosell R, Daniel C, Ramlau R, Szczesna A. Constenla M, Mennecier B. Randomized phase II study of cetuximab in combination with cisplatin $(\mathrm{C})$ and vinorelbine $(\mathrm{V})$ vs $\mathrm{CV}$ alone in the first-line treatment of patients (pts) with epidermal growth factor receptor (EGFR)-expressing advanced non-small-cell lung cancer (NSCLC). Proc Am Soc Clin Oncol. 2004; 23: 618a.

103. Lambert J. Drug-conjugated monoclonal antibodies for the treatment of cancer. Current Opinion in Pharmacology. 2005; 5: 543-549.

104. Scott AM, Renner C. Tumour antigens recognised by antibodies. In: Encyclopaedia of life sciences. Londres: Nature Publishing Group, Macmillan; 2001: 1-7.

105. Raez LE, Fein S, Podack ER. Lung Cancer Immunotherapy. Clinical Medicine \& Research. 2005; 3(4): 221-228.

106. Hirschowitz EA, Yannelli JR. Immunotherapy for Lung Cancer. Proc Am Thorac Soc. 2009; 6: 224-232. 